\title{
Negotiating trans-cultural social service partnerships
}

Peter Walker

Peter Walker is a Senior Lecturer with the Social Work and Community Development Department, University of Otago. He has extensive experience within community development organisations, especially community law centres. He teaches and researches in organisational studies of social service and community organisations.

\begin{abstract}
This paper explores trans-cultural organisational partnerships within kaupapa Māori, Pacific people's and mainstream organisations and how such partnerships are formed and maintained. I describe and analyse such partnerships in practice in New Zealand, using Das and Teng's (2001) trust, risk and control schema, focusing on what works and why it works, and outline strategies to enable the implementation of such partnerships to other sites. The research will hopefully be a resource for those working in community development and social service organisations, who intend to enter into trans-cultural partnerships.
\end{abstract}

\section{Introduction}

This paper explores the social dynamics that impact on trans-cultural ${ }^{1}$ organisational partnerships between either Māori, Pacific peoples or mainstream organisations. The case studies presented here highlight these three sites of organisational relationships. This paper specifically addresses how such partnerships are formed and maintained in practice in New Zealand and analyses these partnerships using Das and Teng's (2001) trust, risk and control schema.

Collaboration between non governmental organisations (NGOs) (within the New Zealand context these are mainly seen as third sector community and voluntary sector organisations) and indigenous peoples can have capacity building benefits for both groups, often succeeding where state provision alone has failed (Schwab and Sutherland, 2002). However, such collaborations often allow mainstream NGOs to deliver services to kaupapa Māori groups rather than assist them to develop independent services. My own work (Walker 2007) explored the successful relationship between two NGO community law centres (one Māori, one non-Māori). This paper aims to extend this work to other mainstream and kaupapa Māori organisations that form partnerships in the social services.

Trans-cultural is defined as 'involving, encompassing or extending across two or more cultures' (MerriamWebster Online Dictionary, 2010). 


\section{Studying trans-cultural partnerships}

The path towards such arrangements seems to rest on a sharing of power, the building of trust and a commitment to learn and appreciate difference (Walker, 2007), equitable decision making processes and a substantial time commitment to initiate and maintain communication, build trust and capacity (Lyver, 2005). Gray (2005) suggests that the preferred approach is dialogical whereby we engage with humility and curiosity in conversations with others about our differing cultures '...with the mind of a learner rather than an expert' (2002, p. 237)

A further element found in the study of trans-cultural partnerships is trust: Trust is more likely to be fostered within partnerships 'where both sides seem ready to place some level of trust in each other' (Bovaird \& Loeffler, 2005, p. 161). Bird and Osland (2006) note that all relationships revolve to some extent around trust; the creation of trust depends on two factors - one's propensity to trust and the perception of the other party's trustworthiness. To assist in this discussion Das \& Teng (2001) identify two elements of trust that can contribute towards a positive experience of partnerships; goodwill and competence trust. Within the New Zealand context the building of trust with Māori organisations requires a model of practice that expands our understanding of partnerships to include Māori cultural paradigms within traditional Eurocentric partnership arrangements by linking kaupapa ${ }^{2}$ (philosophy/agenda) with tikanga ${ }^{3}$ (customs, values beliefs, attitudes) and kanohi ke te kanohi $^{4}$ (face-to-face communication) (Walker, 2004).

The overall consensus among the commentators is that, although it is possible to work collaboratively with little or no trust between partners, the most successful partnerships have, and through ongoing contact and hard work maintain, a strong level of mutual trust.

\section{Trust, control and risk typology}

In analysing the relationships in this study I use the trust, control and risk typology developed by Das and Teng (2001) to deconstruct and analyse partnerships. This typology drawn from business literature to analyse cross country business organisational partnerships, links trust, risk and control (see Figure one) with trust and control reducing risk in a partnership relationship. Trust is viewed as having two separate modes; goodwill and competence. Goodwill trust is one's good faith, good intentions and integrity prior to entering into a relationship being based upon an organisation's reputation over time. Goodwill trust reduces the risk of opportunistic behaviour thus reducing the level of relational risk. In contrast competence trust, based on the various resources and capabilities of an organisation, reduces performance risk. An organisation's competence that it will undertake and complete tasks successfully.

The second dimension control has three modes; behaviour, output and social control, usually grouped as formal (behaviour and output) and informal (social). Behaviour con-

Kaupapa is '... the focus, aims or direction of an organisation' (Walker, 2004, p. 164).

Tikanga is '... the overarching protection or the cultural paradigm in which organisations that identify as kaupapa Māori operate' (ibid, p. 163).

4 Kanohi ke ti kanohi is '... an essential part of the hui (meeting) process for Māori where 'It is important to be able to front up in a hui situation in order to debate the issues 'face to face' [kanohi ki te kanohi], where all involved are able to give voice to their concerns, emotionally and spiritually.' (Bishop 1996, p. 197). 
trol, being understandings or agreements on dividing activities between partners, reduces relational risk. Output control, exercised through the monitoring of performance, helps to reduce performance risk, thus building on behaviour control to link partners co-operating with meeting agreed upon performance standards. Social control in contrast seeks to establish a common culture and/or values between partners through a socialisation and consensus making process.

The third dimension risk has two modes, relational and performance risk. Relational risk, which may lead to the potential for opportunistic behaviour, is reduced by goodwill trust linked to social control. Performance risk, the possibility that set objectives are not achieved through a lack of skills or resources, is reduced by competence trust linked to formal control.

Figure one. Integrated framework of trust, control and risk within partnerships.

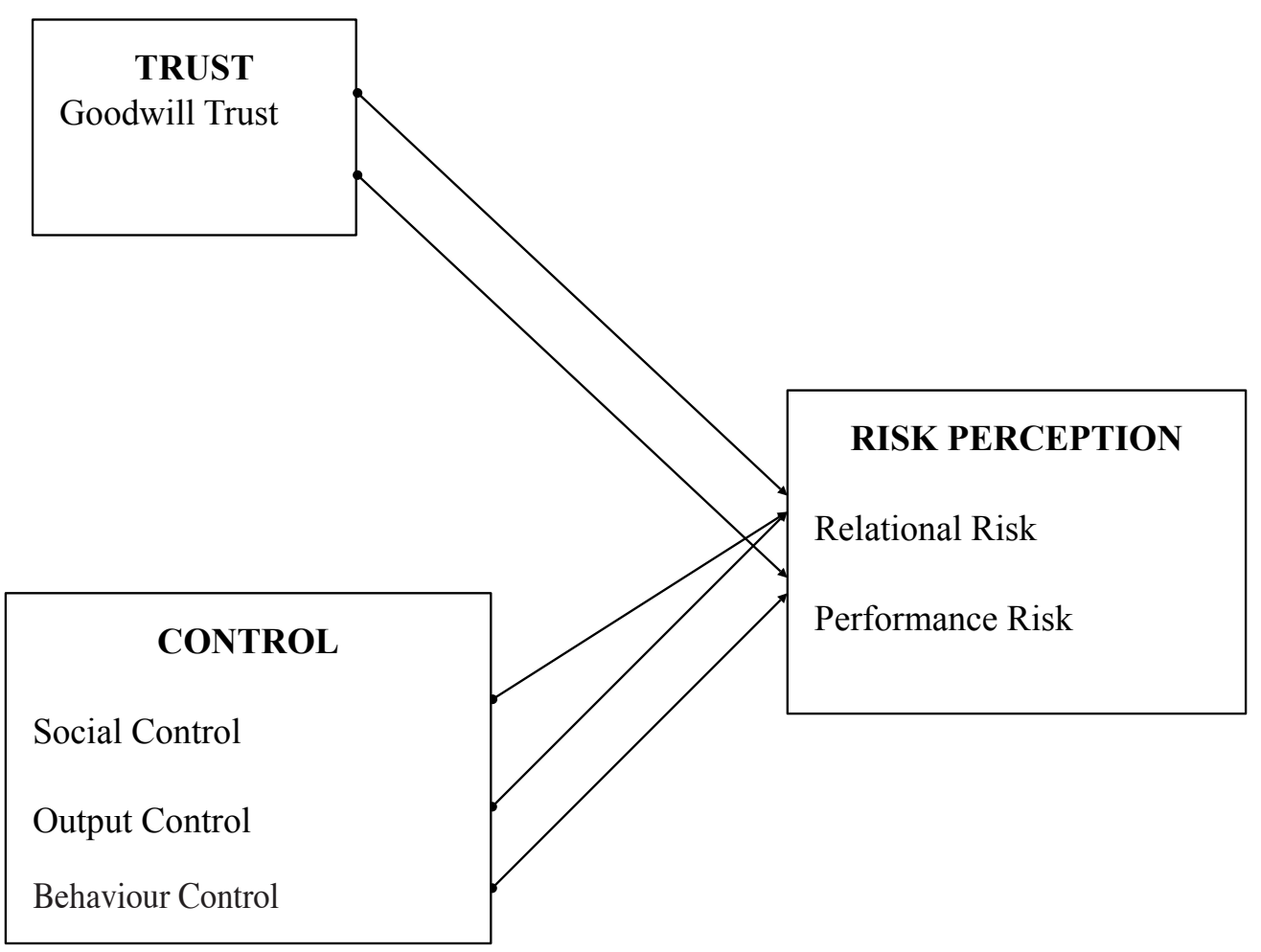

\section{Research method}

As practice orientated research this work describes and analyses the trans-cultural partnership arrangements of six social support, community development and health provision organisations in New Zealand. The case examples studied are all traditional outsider observation of partnerships in the current context. This research was conducted in 2009 through a historical document analysis (when available) and an in-depth analysis of interviews with key figures within the organisations; the transcripts of the interviews were checked by the 
respondents for accuracy. I sincerely thank the respondents for their time and willingness to share their partnership practices for this research.

\section{The partnerships}

Presbyterian Support Northern (PSN) - a large third-sector social support agency offering a wide range of social services for the people of the upper North Island. PSN wished to form partnerships with the various iwi (Māori tribes) social services in their region to improve service delivery to Māori clients and foster development for their Māori staff.

Waipareira Pasifica (WP) - a now defunct service that provided community-based social services to Māori and Pacific peoples of West Auckland. The partnership between Waipareira Trust and West Fono Health Trust took the form of a joint venture company Waipareira Pasifica. In 2008 it was decided that the partnership would end and WP would cease to exist.

Arai te Uru Whare Hauora (ATUWHO) - a kaupapa Māori health and social service provider based in Dunedin but operating across the Otago province They have partnership arrangements with other social service providers in the wider Otago provincial region. They are dependent on District Health Board and Government contracts to supply health, education and social services that focus on the health and wellbeing of whanau (extended family). ATUWHO only enters into partnership relationships to enable their clients access to services provided by the partner organisation.

Otara Community Law Centre (Otara CLC) - a community law centre providing general advice, education, information and representation for the people of South Auckland. They have good relationships with the social service and community support groups in the wider South Auckland area. The relationships with Pacific people's groups and communities are based on the personal involvement of the staff at the Otara CLC in those communities.

Wellington Community Law Centre (Wellington CLC) - a community law centre providing general advice, education, information and representation for the people of Wellington. They are well positioned in the community having always strived to operate from a community development perspective. WCLC have three societal groups that they form trans-cultural partnerships with - tangata whenua, Pacific peoples and refugee and migrant people's organisations.

Te Ratonga Ture (TRT) - is a specialist community law centre providing general advice, education, information and representation for the Māori people of Wellington. TRT has trans-cultural partnerships with the other community law centres in the Wellington region (Wellington CLC, Hutt Valley CLC and Porirua CLC). There is an informal agreement across the four community law centres that TRT works across the whole region with Māori clients and their whanau.

\section{Analysis of partnerships}

\section{Trust}

Goodwill trust was present in these partnerships in the following ways: 
An acknowledgment that non-Māori organisations had obligations under the Treaty of Waitangi and should seek relationships with the various iwi in their geographical area. In addition there was a willingness to seek relationships with kaupapa Māori organisations built on an acknowledgement of self-determination rights. This was supported by a willingness to engage in a face-to-face, leader-to-leader, process to foster respect which meant that the partnerships had approval from the leaders of both sides of the partnerships at the start of the relationship and acknowledged the leadership structure within iwi.

Goodwill trust was built on the shared experience of providing services to Māori at a local level and of being resistant to state top-down policy initiatives articulated through funders' priorities. This was built on an active engagement of the staff and organisations in their community through methods such as active networking and by hosting community accountability days to seek direction and input from the community. In addition there was an acknowledgement of shared values, norms and passion for the work that the organisations undertake.

The second mode of trust, competence trust suggests that there is a high probability that the organisation will accomplish tasks successfully. Competence trust was built on the historical record of each organisation of providing quality services to their communities over the long term. This assessment was undertaken by monitoring how the other organisation provides services to the community through interaction in networks and through feedback from shared clients and through previous shared work (resource production and submissions). In addition competence trust was enhanced by recognising the various expertise of each of the organisations, demonstrated through the willingness to refer clients to each other.

Competence trust is supported by an ongoing and active process whereby staff and managers of both organisations meet and introduce themselves and their areas of expertise to each other. As a further engagement process the secondment of staff between organisations meant that such partnerships were not just rhetorical but had substance in practice by the sharing of ideas, methods of working and the rationale for working in particular ways.

However competence trust was diminished when non-Māori organisations questioned the competence of staff and accountability mechanisms of Māori organisations.

\section{Control}

Most of the partnerships in this study eschewed formal control mechanisms, with only two partnerships having a signed agreement setting out the parameters of the arrangement to ensure performance and monitor outputs. MOUs were not valued highly by the partnerships as they are seen to be prone to being established and imposed for rhetorical reasons rather than the increase in well-being for the clients. Having no written agreements was seen as being positive as the partnerships rely on real relationships between staff and volunteers. However such arrangements are at risk if staff change and further, they are also seen as being very difficult to evaluate and monitor.

Formal control was built on agreements to refer clients to provide a holistic service and to establish and maintain the secondment of staff process. In addition there were agreements within the monitoring provisions of funding contracts especially when there was a shared external funding contract. 
Social control was expressed through a mutual understanding of, and commitment to acknowledging obligations under the Treaty of Waitangi and/ or a commitment to kaupapa Māori people's self-determination rights. This was built on the interaction of management and governance across all levels of the partnerships to promote a more context-embedded way of working that encompassed practice from all partnerships. This enabled a development of understanding by observing culturally appropriate practice through the secondment of workers to build expertise across the partnerships and a directing of clients to appropriate services to meet their needs rather than holding on to them within one organisation.

\section{Risk}

The final dimension, risk has two modes, relational and performance. Relational risk may lead to the potential for opportunistic behaviour but is reduced by goodwill trust linked to social control.

Relational risk was identified through the competitive funding environment and external contract compliance issues of non-Māori organisations seeking tokenistic partnerships to fulfil contract requirements rather than for the benefits that the partnership may offer, with such partnerships being seemingly more important at a rhetorical level than actual sharing of services. This was accentuated by not acknowledging the different expertise held within the partner organisation or by a lack of communication between the partners.

Another identified risk factor was mainstream organisations relying on the relationship with the kaupapa Māori organisation to fulfil Treaty of Waitangi obligations at the expense of forming a direct relationship with iwi.

Relational risk was reduced by creating a shared vision of beneficial practice, having open communication across all levels of the partnerships and intermingling of staff through secondment. Internal diversity training of staff also led to an increase of understanding of cultural difference and ways of working.

Performance risk was identified through a lack of strategic planning combined with a lack of key performance indicators and confused lines of authority to governance. Such risk was accentuated by the competitive funding environment that put Māori workers in a partner organisation in an antagonistic relationship with the Māori organisation.

\section{Discussion}

The lessons to be learned from the partnerships outlined in this paper offer an insight into the possible future of social services in New Zealand where there is an intent to enter into trans-cultural relationships.

The ongoing desire of organisations to support their service users was one of the most cited reasons to enter into trans-cultural partnerships and was one of the key drivers of the partnership desire. Partner organisations provide care and support that their organisation was unable to provide, thus the arrangement enabled holistic, wrap-around support for the service users. To cement the relationship the ongoing interaction of both staff and governance was deemed vital with mechanisms such as: the secondment of staff to build skills; regular governance meetings to build consensus and a shared vision; and frequent 
staff contact to build goodwill and competence trust, reinforcing the common values and mutual understanding between the partners.

External elements such as the competitive funding environment and contract compliance requirements were seen as damaging to partnership relations and thus increased relational risk. Competitive funding placed partner organisations in an antagonistic relationship with Māori programmes and workers in the mainstream organisation in direct competition with the kaupapa Māori organisation to secure funds to provide targeted services to Māori service users. The practice by state funders of requiring mainstream social services to provide evidence of interactions with kaupapa Māori organisations or iwi as part of their contract compliance has the consequence of encouraging mainstream organisations to form transcultural relationships for rhetorical reasons.

One of the key issues in building trust with kaupapa Māori organisations was for the nonMāori organisation to acknowledge that they had Treaty of Waitangi obligations and that they should seek relationships with iwi and kaupapa Māori organisations in their geographical area. In seeking such relationships there was an acknowledgment that kaupapa Māori were representations of self-determination. In two of the case studies these acknowledgments were also supported by an admission by the non-Māori organisation that they were not a bicultural organisation and had much to learn from their Māori partners. Such recognitions form the underpinning social control in the relationships. This supports an earlier finding (Walker 2007) that it is possible to give substance to Treaty of Waitangi obligations at a local organisational level.

\section{Conclusion}

The partnerships highlighted by this study suggest that building trans-cultural partnerships is an ongoing and active process; it is dialogical to the extent that the partnerships are essentially conversations between organisations entered into with humility and curiosity. Through such dialogue organisations can learn from and honour and value cultures and in so doing allow new partnership forms to emerge.

The grouping together of the various components of trust, control and risk allows the possibility of highlighting what practices work to build trust and reduce risk and what control mechanisms are utilised. Thus it is possible to understand the makeup and mechanisms of the partnerships and draw lessons and guidance from the organisations' experiences.

Building trust in a trans-cultural partnership seems to rest on the acknowledgment of kaupapa Māori and Pacific people's self-determination rights and a desire to offer service users holistic service provision. What is seen as especially problematic is mainstream organisations entering into such arrangements solely to meet the requirements of funders; such practices undermine trust and are cynical and shallow attempts to meet contract obligations. When entering trans-cultural partnerships with kaupapa Māori and Pacific people's organisations, mainstream organisations need to exhibit a commitment over time to relating to the Māori or Pacific people's organisations' worldview, values and processes. In this way they can enter with their partners into a dialogue of a shared vision of beneficial practice for their clients, their communities and their organisations. Such strategic action is required if the potential of trans-cultural partnerships is to be realised in terms of equity and self-determination. 


\section{References}

Bird, A., \& Osland, J. (2006). Making sense of intercultural collaboration. International Studies of Management and Organization, 35(4), 115-132.

Bovaird, T., \& Loeffler, E. (2005). Communities trust and local governance failure. In S. Watson and A. Moran (Eds). Trust, risk and uncertainty, (pp. 143-162). Basingstoke: Palgrave Macmillan.

Das, T. \& Teng, B-S. (1998). Between trust and control: Developing confidence in partner co-operation in alliances. Academy of Management Review, 23, 491-512.

Das, T. \& Teng, B-S. (2001). Trust, control and risk in strategic alliances: An integrated framework. Organizational Studies, 22, 251-283.

Flyvbjerg, B. (2001). Making social science matter. Cambridge: Cambridge University Press.

Gray, B. (1989). Collaborating: Finding common ground for multiparty problems. San Francisco: Josey Bass.

Gray, M. (2005). Dilemmas of international social work: Paradoxical processes in indigenisation, universalism and imperialism. International Journal of Social Welfare, 231-238.

Lyver, P. (2005). Co-managing environmental research: Lessons from two cross-cultural research partnerships in New Zealand. Environmental Conservation, 32(4), 365-370.

Schwab, R.G., \& Sutherland, D. (2002). Philanthropy, non-government organizations and indigenous development. Paper No. 242/2002 Centre for Aboriginal Economic Policy Research.

Walker, P. (2004) Partnership models within a Maori social service provider. International Journal of Social Welfare, 158-169.

Walker, P. (2005). The Treaty of Waitangi as the foundation for social service partnerships. Social Work Review, 17(4), 15-20.

Walker, P. (2007) Trust risk and control within an indigenous-non-indigenous social service partnership, International Journal of Social Welfare, 16, 281-290. 